\title{
Acute effects of fatty acids on insulin secretion from rat and human islets of Langerhans
}

\author{
C Gravena ${ }^{1,2}$, P C Mathias ${ }^{2}$ and S J H Ashcroft ${ }^{1}$ \\ 'Nuffield Department of Clinical Laboratory Sciences, John Radcliffe Hospital, Headington, Oxford OX3 9DU, UK \\ 2Department of Cell Biology and Genetics, University of Maringá, 87020-900 Maringá, Brazil \\ (Requests for offprints should be addressed to S Ashcroft; Email: stephen.ashcroft@ndcls.ox.ac.uk)
}

\begin{abstract}
Fatty acids have both stimulatory and inhibitory effects on insulin secretion. Long-term exposure to fatty acids results in impaired insulin secretion whilst acute exposure has generally been found to enhance insulin release. However, there are conflicting data in the literature as to the relative efficacy of various fatty acids and on the glucose dependency of the stimulatory effect. Moreover, there is little information on the responses of human islets in vitro to fatty acids. We have therefore studied the acute effects of a range of fatty acids on insulin secretion from rat and human islets of Langerhans at different glucose concentrations.

Fatty acids $(0.5 \mathrm{mM})$ acutely stimulated insulin release from rat islets of Langerhans in static incubations in a glucose-dependent manner. The greatest effect was seen at high glucose concentration $(16.7 \mathrm{mM})$ and little or no response was elicited at 3.3 or $8.7 \mathrm{mM}$ glucose. Longchain fatty acids (palmitate and stearate) were more effective than medium-chain (octanoate). Saturated fatty acids (palmitate, stearate) were more effective than unsatu-

rated (palmitoleate, linoleate, elaidate). Stimulation of insulin secretion by fatty acids was also studied in perifused rat islets. No effects were observed at $3.3 \mathrm{mM}$ glucose but fatty acids markedly potentiated the effect of $16.7 \mathrm{mM}$ glucose. The combination of fatty acid plus glucose was less effective when islets had been first challenged with glucose alone. The insulin secretory responses to fatty acids of human islets in static incubations were similar to those of rat islets. In order to examine whether the responses to glucose and to fatty acids could be varied independently we used an animal model in which lactating rats are fed a low-protein diet during early lactation. Islets from rats whose mothers had been malnourished during lactation were still able to respond effectively to fatty acids despite a lowered secretory response to glucose.

These data emphasise the complex interrelationships between nutrients in the control of insulin release and support the view that fatty acids play an important role in glucose homeostasis during undernutrition.

Journal of Endocrinology (2002) 173, 73-80
\end{abstract}

\section{Introduction}

There is increasing evidence that fatty acids play a role in stimulus response coupling in the pancreatic beta-cell (McGarry \& Dobbins 1999, Grill \& Qvigstad 2000). Early in vivo studies demonstrated that acute elevation of plasma free fatty acids augmented glucose-stimulated insulin secretion (Greenough et al. 1967, Seyffert \& Madison 1967, Balasse \& Ooms 1973, Crespin et al. 1973), although there was debate as to what extent this represented a direct effect of fatty acids on the beta-cell. More recent studies have confirmed that fatty acids do indeed directly influence beta-cell function; however, the response is far from simple. In both rodents and humans it has been shown that during starvation fatty acids are essential to permit basal insulin secretion and to allow a secretory response to glucose on termination of the fast (Stein et al. 1996, Boden et al. 1998, Dobbins et al. 1998, McGarry \& Dobbins 1999). However, prolonged exposure to elevated fatty acids, as may occur in type 2 diabetes, results in impairment of beta-cell secretory function (Sako \& Grill 1990, Gatti et al. 1992, Elks 1993, Zhou \& Grill 1994, Bollheimer et al. 1998).

The present study is focused on the acute stimulatory effect of fatty acids on insulin secretion. We wished to establish the glucose concentration dependence and specificity of their effect in rodent islets, since conflicting data are reported in the literature (Crespin et al. 1973, Lardinois et al. 1987, Conget et al. 1994, Opara et al. 1994, Rasmussen et al. 1996, Joannic et al. 1997, Alstrup et al. 1999, Warnotte et al. 1999); to assess to what extent the data in rat islets apply to human islets; and to examine whether the stimulatory effect of fatty acids on insulin secretion are preserved in islets from rats whose mothers were fed on a low-protein diet during early lactation and which show a decreased secretory response to glucose itself (Moura et al. 1996). 


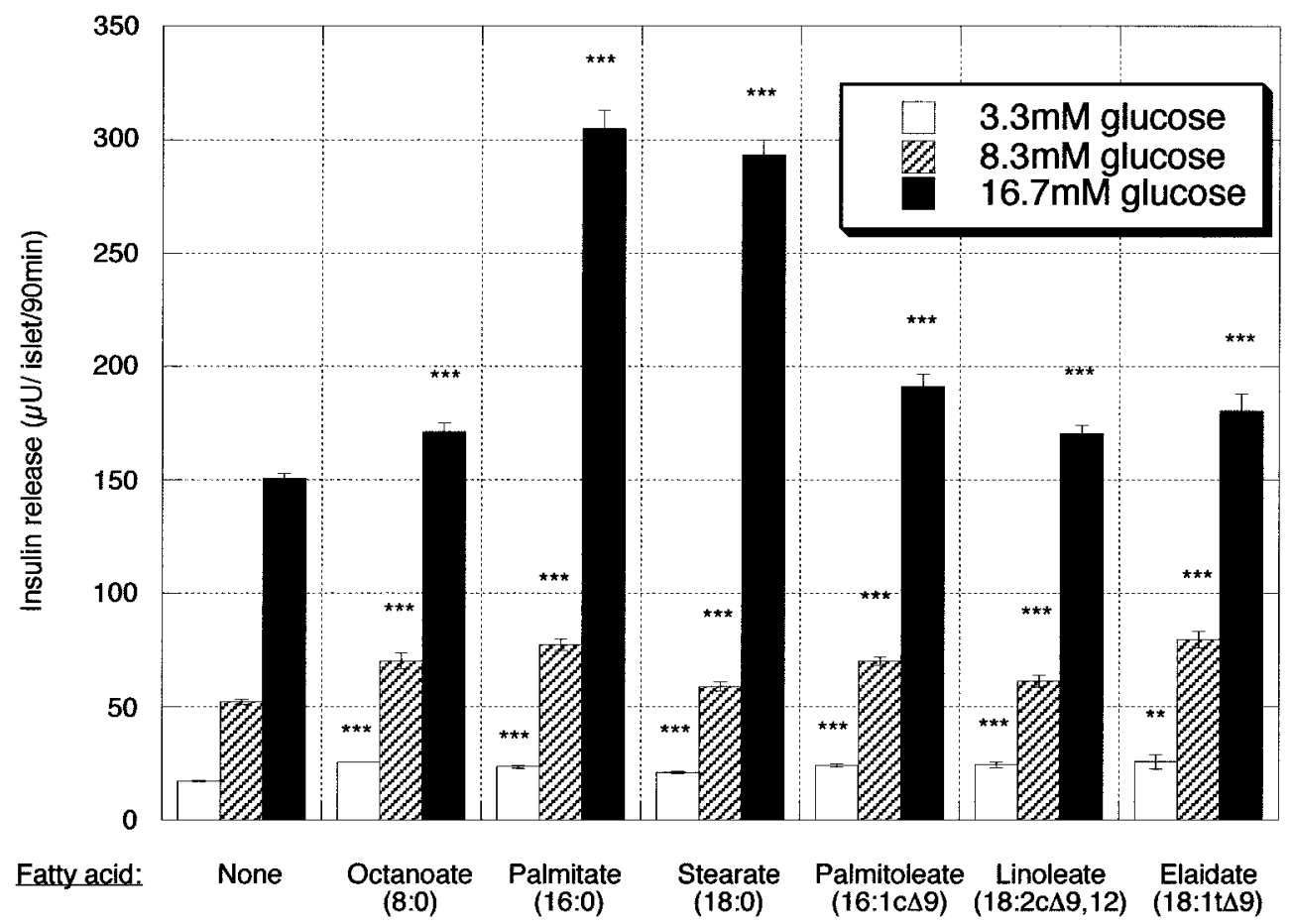

Figure 1 Acute effects of fatty acids on insulin release from rat islets in batch incubations. Batches of five islets were incubated for $90 \mathrm{~min}$ with glucose at the concentrations indicated in the presence or absence of $0.5 \mathrm{mM}$ fatty acid. Data are means \pm S.E.M. for 30 batches of islets in the absence and 15 batches of islets in the presence of fatty acid. ${ }^{* *} P<0 \cdot 001,{ }^{* *} P<0.01$ for increase in insulin secretion in the presence of fatty acid plus glucose compared with the rate in the presence of the same glucose concentration alone.

\section{Materials and Methods}

\section{Materials}

Fatty acids were obtained from Sigma Chemical Co. (Poole, Dorset, UK). Solid-phase anti-guinea pig serum (Sac-Cel) was from IDS (Boldon, Tyne and Wear, UK). ${ }^{125}$ I-labelled insulin was from NEN Life Science Products, Hounslow, Middx, UK. Low-protein rat diet was obtained from Hope Farms, Woerden, Netherlands. Other chemicals, of reagent grade, were from Sigma Chemical Co. or BDH-Merck (Lutterworth, Leics, UK).

\section{Solutions}

The incubation medium was a Hepes-buffered Krebs bicarbonate medium (HKB) with the following composition (mM): $\mathrm{NaCl} 119 ; \mathrm{KCl} 4 \cdot 75 ; \mathrm{NaHCO}_{3} 5 ; \mathrm{CaCl}_{2}$ 2.54; $\mathrm{KH}_{2} \mathrm{PO}_{4} 1 \cdot 2 ; \mathrm{MgSO}_{4} 1 \cdot 2$; Hepes (pH 7.4) 20. The medium was supplemented with $1 \%$ fatty acid-free BSA and contained glucose at the concentrations indicated in the presence or absence of $0.5 \mathrm{mM}$ fatty acid.

To prepare stock fatty acid solutions, fatty acids $(1 \mathrm{mmol}$ ) were dissolved in 10-15 $\mathrm{ml}$ ethanol and $200 \mu \mathrm{l}$ $5 \mathrm{M} \mathrm{NaOH}$ were added. The solutions were evaporated to dryness overnight in a stream of air. Ten millilitres of water were added and the mixture placed on a hot-plate. One hundred and fifty millilitres of ice-cold $13.3 \%$ fatty acidfree albumin in HKB were slowly added with stirring and the volume adjusted to $200 \mathrm{ml}$. For linoleate an alternative procedure was followed. One gram of fatty acid-free albumin was dissolved in $10 \mathrm{ml} 20 \mathrm{mM}$ Tris buffer at $37^{\circ} \mathrm{C}$. Linoleic acid $(10 \mathrm{mM})$ was dissolved in $5 \mathrm{ml}$ toluene and $25 \mu \mathrm{l} 2 \mathrm{M} \mathrm{KOH}$ were added. The solution was vortexed and evaporated to dryness under nitrogen at $50{ }^{\circ} \mathrm{C}$. Five millilitres of the warm albumin solution were added and the tube contents mixed and put on a rotary mixer for at least $10 \mathrm{~min}$.

Samples of incubation medium were diluted and stored in phosphate buffer $(40 \mathrm{mM}, \mathrm{pH} 7 \cdot 4)$ containing $0 \cdot 025 \%$ Merthiolate and $0 \cdot 1 \%$ albumin (PAM).

\section{Preparation of islets of Langerhans}

Rat islets were prepared by a collagenase method (Sutton et al. 1986) from the pancreases of 2-month-old Wistar rats. Animals were deprived of food the evening before they were used for islet preparation. Three batches of human islets were used in these studies. The islets were isolated from heart-beating adult cadaver organ donors and supplied by the human islet facility at the University of Leicester, Leicester, UK. 

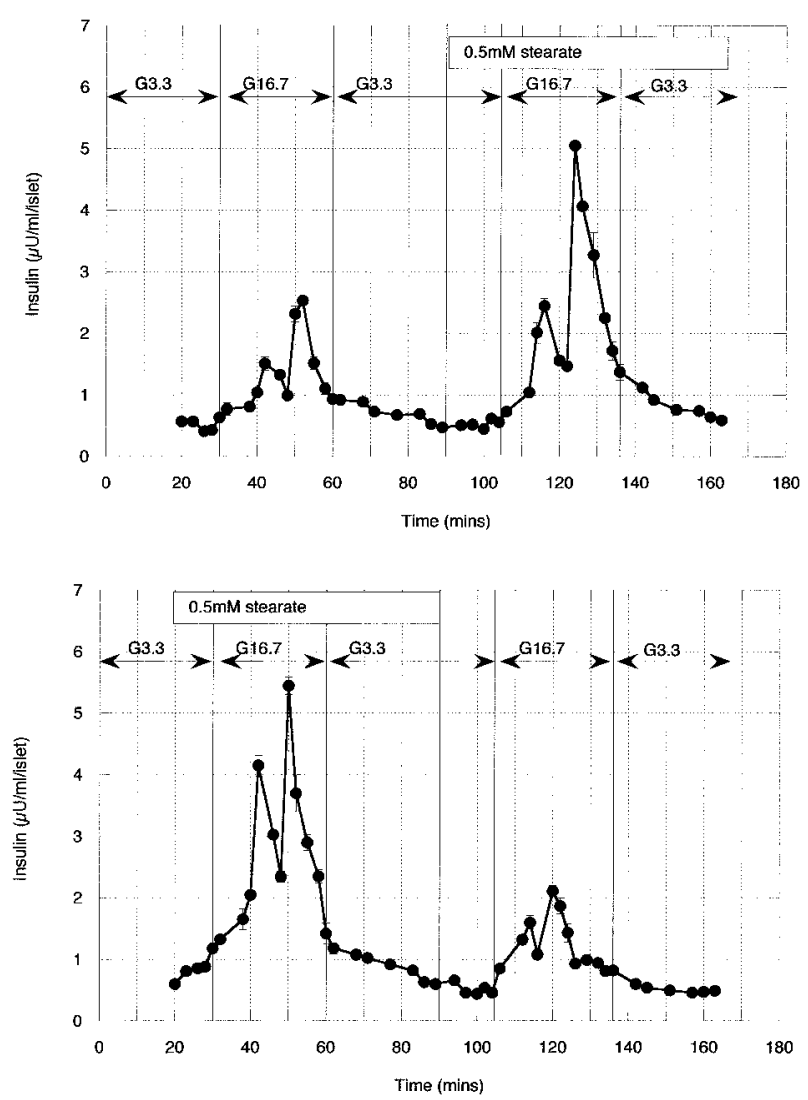

Figure 2 Potentiation by stearate of glucose-stimulated insulin release from perifused rat islets. Islets were perifused according to the protocols described under Methods. Each batch of 100 islets was exposed to two stimulatory periods, either $16.7 \mathrm{mM}$ glucose (G16.7) followed by $16.7 \mathrm{mM}$ glucose plus $0.5 \mathrm{mM}$ stearate (Protocol A, upper panel) or the converse (Protocol B, lower panel). The stimulatory periods were separated by a non-stimulatory period in $3.3 \mathrm{mM}$ glucose $(\mathrm{G} 3 \cdot 3)$. Data are means \pm S.E.M. for four separate experiments.

\section{Insulin secretion}

Two procedures were used to study the effect of fatty acids on insulin secretion. In static incubations, batches of five rat or human islets were incubated for $90 \mathrm{~min}$ at $37^{\circ} \mathrm{C}$ in $0.6 \mathrm{ml} \mathrm{HKB}$ containing $1 \%$ fatty acid-free BSA and glucose and fatty acids at the concentrations stated. For perifusion studies, 100 islets were placed on to a $1 \mathrm{ml}$ column of Biogel P2 and perifused with HKB containing $1 \%$ fatty acid-free BSA and the desired additions at a flow rate of $1 \mathrm{ml} / \mathrm{min}$. The first procedure (Protocol A) consisted of an equilibration period of $60 \mathrm{~min}$ in $3.3 \mathrm{mM}$ glucose followed by a $30 \mathrm{~min}$ exposure to $16.7 \mathrm{mM}$ glucose. The glucose concentration was then lowered again to $3.3 \mathrm{mM}$. After $15 \mathrm{~min}, 0.5 \mathrm{mM}$ of the fatty acid to be tested was added to the perifusion medium and after a further $15 \mathrm{~min}$ the glucose concentration was raised to $16.7 \mathrm{mM}$ in the continued presence of the fatty acid. After
Table 1 Insulin secretory responses of perifused rat islets to glucose and fatty acids (FAs). Rat islets were perifused according to the protocols described in Materials and Methods. Each batch of islets was exposed to two 30 min stimulatory periods. In Protocol A the first stimulus was $16.7 \mathrm{mM}$ glucose and the second was $16.7 \mathrm{mM}$ glucose plus $0.5 \mathrm{mM}$ FA. In Protocol B the first stimulus was $16.7 \mathrm{mM}$ glucose plus $0.5 \mathrm{mM}$ FA and the second was $16.7 \mathrm{mM}$ glucose alone. The stimulations were separated by a non-stimulatory period $(3.3 \mathrm{mM}$ glucose). The table presents the integrated insulin secretion during the two stimulatory periods. Data are means \pm S.E.M. of four separate experiments

\begin{tabular}{|c|c|c|c|c|}
\hline & \multirow[b]{2}{*}{ Protocol } & \multicolumn{2}{|c|}{$\begin{array}{l}\text { Insulin secretion ( } \mu \mathrm{U} / \text { islet) } \\
\text { in response to: }\end{array}$} & \multirow[b]{2}{*}{$P$} \\
\hline & & Glucose & Glucose +FA & \\
\hline \multicolumn{5}{|l|}{ FA } \\
\hline \multirow[t]{2}{*}{ Octanoate } & A & $23 \cdot 9 \pm 1 \cdot 1$ & $23 \cdot 1 \pm 1 \cdot 3$ & NS \\
\hline & B & $21 \cdot 5 \pm 0 \cdot 7$ & $28 \cdot 8 \pm 0 \cdot 9$ & $<0.001$ \\
\hline \multirow[t]{2}{*}{ Palmitate } & A & $28 \cdot 1 \pm 1 \cdot 1$ & $37 \cdot 6 \pm 1 \cdot 7$ & $<0 \cdot 01$ \\
\hline & B & $30 \cdot 2 \pm 1 \cdot 0$ & $41 \cdot 9 \pm 2 \cdot 1$ & $<0 \cdot 001$ \\
\hline \multirow[t]{2}{*}{ Stearate } & A & $37 \cdot 2 \pm 1 \cdot 6$ & $58 \cdot 9 \pm 2 \cdot 9$ & $<0.001$ \\
\hline & $\mathrm{B}$ & $33 \cdot 7 \pm 1 \cdot 3$ & $76 \cdot 8 \pm 2 \cdot 8$ & $<0 \cdot 001$ \\
\hline \multirow[t]{2}{*}{ Palmitoleate } & A & $21 \cdot 0 \pm 0 \cdot 8$ & $22 \cdot 8 \pm 0 \cdot 6$ & NS \\
\hline & $\mathrm{B}$ & $19 \cdot 3 \pm 1 \cdot 1$ & $33 \cdot 1 \pm 0 \cdot 9$ & $<0.001$ \\
\hline \multirow[t]{2}{*}{ Linoleate } & A & $22 \cdot 8 \pm 1 \cdot 3$ & $22 \cdot 5 \pm 1 \cdot 4$ & NS \\
\hline & B & $20 \cdot 5 \pm 0 \cdot 8$ & $26 \cdot 1 \pm 1 \cdot 1$ & $<0 \cdot 01$ \\
\hline \multirow[t]{2}{*}{ Elaidate } & A & $25 \cdot 6 \pm 1 \cdot 4$ & $34 \cdot 6 \pm 1 \cdot 6$ & $<0 \cdot 01$ \\
\hline & $\mathrm{B}$ & $19 \cdot 9 \pm 1 \cdot 2$ & $33 \cdot 5 \pm 1 \cdot 1$ & $<0 \cdot 001$ \\
\hline
\end{tabular}

$30 \mathrm{~min}$ the glucose concentration was lowered again to $3.3 \mathrm{mM}$ in the presence of fatty acid. In parallel a second perifusion procedure (Protocol B) was carried out in which the first stimulation was in the presence of glucose plus fatty acid and the second was with glucose alone. This procedure was adopted in order to control for the possible effect of order of exposure to stimulant on insulin release rates. Samples of incubation and perifusion media were diluted in PAM and stored frozen until assay.

\section{Dietary manipulation of lactating rats}

Female rats were fed a normal laboratory diet during pregnancy. After delivery each lactating dam was kept with six pups and the rats distributed into two groups. In the test group, all dams received a low-protein (4\%) diet during the first 12 days of lactation. In the control group all dams received a normal diet during lactation. After 21 days the pups were separated from the mothers and received a control diet for 60 days at which time they were used for preparation of islets of Langerhans.

\section{Assay of insulin}

Insulin was a measured by RIA (Molnár et al. 1995) using a solid state second antibody (Sac-Cel) for separation of bound and free insulin. 


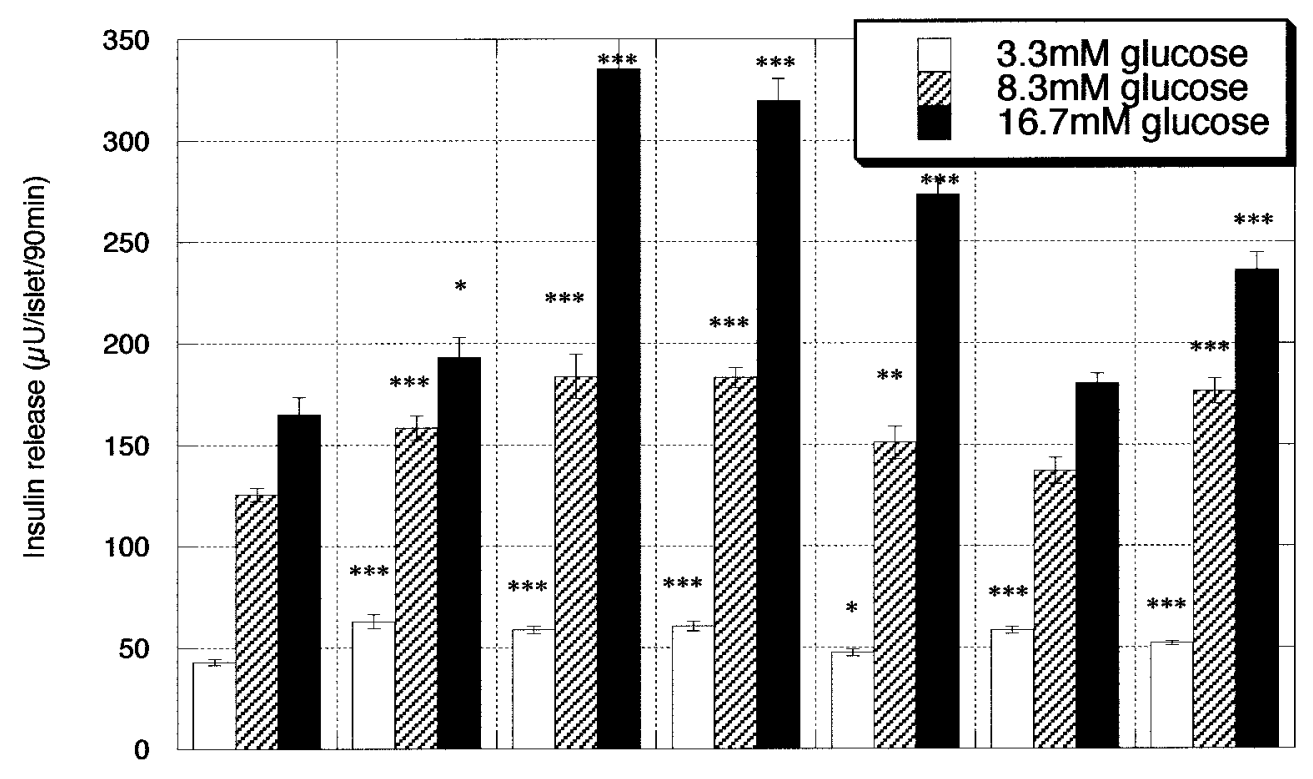



Figure 3 Acute effects of fatty acids on insulin release from human islets in batch incubations. Batches of five islets were incubated for 90 min with glucose at the concentrations indicated in the presence or absence of $0.5 \mathrm{mM}$ fatty acid. Data are means \pm S.E.M. for 22 batches of islets. ${ }^{* * *} P<0 \cdot 001,{ }^{* *} P<0 \cdot 01$ and ${ }^{*} P<0.05$ for increase in insulin secretion in the presence of fatty acid plus glucose compared with the rate in the presence of the same glucose concentration alone.

\section{Data analysis}

Data are expressed as means \pm S.E.M. for the number of observations stated. Statistical significance was evaluated using a two-tailed Student's $t$-test.

\section{Results}

Acute effects of fatty acids on insulin secretion from rat islets of Langerhans

The mean insulin secretory rates from normal rat islets in batch incubations in the presence of $3 \cdot 3,8.6$ and $16.7 \mathrm{mM}$ glucose were $17 \cdot 3 \pm 0 \cdot 3,52 \cdot 1 \pm 1 \cdot 2$ and $150 \cdot 5 \pm 2 \cdot 1 \mu \mathrm{U} /$ islet per $90 \min (n=30)$ respectively. Fatty acids produced marked stimulatory effects on insulin secretion. The dependence on fatty acid chain length is shown in Fig. 1. Octanoate (8:0) produced a very small, although significant $(P<0 \cdot 001)$, increase in insulin secretion at all glucose concentrations tested. Palmitate (16:0) and stearate (18:0) elicited similar very small effects at 3.3 and $8.6 \mathrm{mM}$ glucose; however, both fatty acids produced a marked potentiation $(\sim 100 \%)$ of insulin release stimulated by $16.7 \mathrm{mM}$ glucose. The effects of saturation are also given in Fig. 1. The presence of double bonds in the fatty acid chain markedly reduced the secretory response to the fatty acid. Thus the effects of palmitoleate $(16: 1 \mathrm{c} \Delta 9)$ and linoleate $(18: 2 c \Delta 9,12)$ in the presence of $16.7 \mathrm{mM}$ glucose were greatly reduced compared with the rates seen with palmitate. The presence of a trans double bond in elaidate $(18: 1 \mathrm{t} \Delta 9)$ also resulted in reduced stimulatory ability.

In the perifusion system $0.5 \mathrm{mM}$ stearate had no effect on insulin release in the presence of $3.3 \mathrm{mM}$ glucose but elicited a marked enhancement of the secretory response to $16.7 \mathrm{mM}$ glucose irrespective of whether the fatty acid was present during the first exposure to high glucose or the second (Fig. 2). Quantification of the perifusion data was carried out by measurement of the area under the curves during the various perifusion periods, and the data are summarised in Table 1. As for the static incubations, the potentiating effect of fatty acids on glucose-stimulated insulin release was most marked with long-chain saturated fatty acids. In this system stearate was more effective than palmitate. The data also revealed that prior exposure to high glucose alone (Protocol A) could influence the subsequent response to glucose plus fatty acid. Thus neither palmitoleate nor linoleate potentiated glucosestimulated insulin release when the islets had first been challenged with $16.7 \mathrm{mM}$ glucose. Octanoate also was only effective (to a small extent) when present during the first exposure to high glucose. 


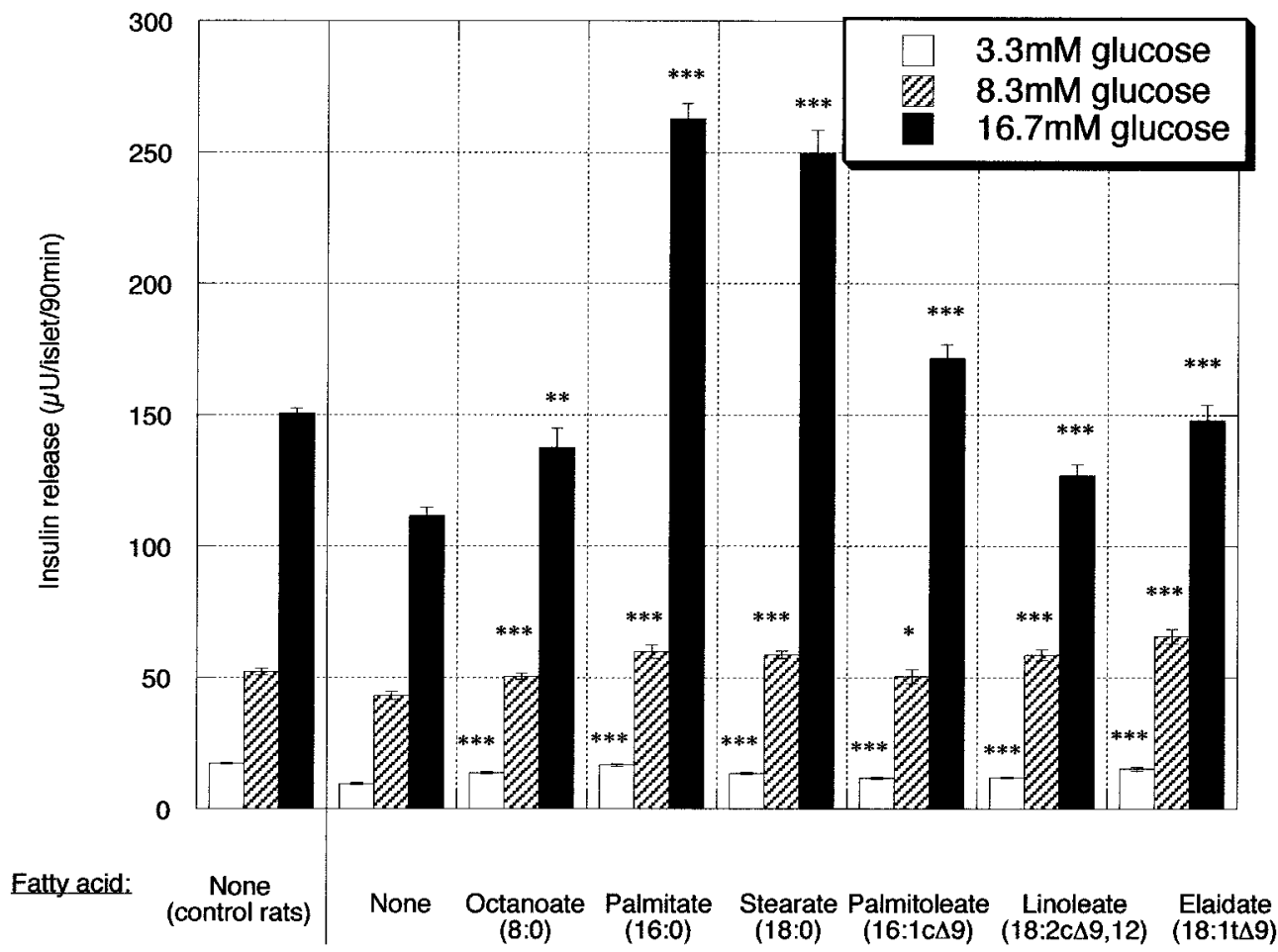

Figure 4 Acute effects of fatty acids on insulin release in batch incubations of islets from rats whose mothers were fed a low-protein diet during the first 12 days of lactation. Islets were incubated for $90 \mathrm{~min}$ with glucose at the concentrations indicated in the presence or absence of $0.5 \mathrm{mM}$ fatty acid. For comparison, the rates of secretion in the absence of fatty acid for islets from control litter mates are shown at the left; these rates are all significantly greater $(P<0 \cdot 001)$ than the rates from the 'malnourished' islets at the same glucose concentration in the absence of fatty acid. Data are means \pm S.E.M. for 21 batches of islets. ${ }^{* * *} P<0 \cdot 001,{ }^{* *} P<0.01$ and ${ }^{*} P<0.05$ for increase in insulin secretion in the presence of fatty acid plus glucose compared with the rate in the presence of the same glucose concentration alone.

Acute effects of fatty acids on insulin secretion from human islets of Langerhans

The mean insulin secretory rates from human islets in batch incubations in the presence of $3 \cdot 3,8.6$ and $16.7 \mathrm{mM}$ glucose were $42.9 \pm 1 \cdot 4,125 \cdot 4 \pm 3 \cdot 4$ and $164 \cdot 7 \pm 8 \cdot 6 \mu \mathrm{U} /$ islet per $90 \mathrm{~min}(n=22)$ respectively. Fatty acids potentiated glucose-stimulated insulin released from human islets in batch incubations. As for rat islets the response was greatest at high glucose concentration and with long-chain saturated fatty acids (Fig. 3).

Effects of maternal malnourishment during early lactation on insulin secretory responses to glucose and fatty acids

Islets from rats whose mothers were fed on a low-protein diet during the first 12 days of lactation had an impaired secretory response to glucose compared with the litter mates whose mothers received normal laboratory diet. In batch incubations the secretory rates at $3.3,8.3$ and $16.7 \mathrm{mM}$ glucose were reduced to $9 \cdot 6 \pm 0 \cdot 4,43.1 \pm 1 \cdot 6$ and $111 \cdot 7 \pm 3 \cdot 1 \mu \mathrm{U} /$ islet per $90 \mathrm{~min}(n=21)$ respectively (all values significantly less $(P<0 \cdot 001)$ than the corresponding values given above for normal rat islets). Despite the reduced response to $16.7 \mathrm{mM}$ glucose, fatty acids still elicited marked potentiating effects (Fig. 4). Indeed the absolute increase in secretion compared with $16.7 \mathrm{mM}$ glucose alone evoked by each fatty acid was virtually identical for the control and 'malnourished' groups. The inhibitory effect of maternal malnutrition on glucose-stimulated insulin release was also clearly evident in perifused islets (Fig. 5). Again, however, fatty acids were capable of increasing insulin release as well as in the control islets. The response to stearate is shown in Fig. 5 and the data for all the fatty acids are quantified in Table 2. In general the islets from the offspring of low-protein diet-fed mothers were more responsive to fatty acids than the control islets. Thus despite a $\sim 50 \%$ reduction in insulin release in response to $16.7 \mathrm{mM}$ glucose alone, secretion rates in the presence of $16.7 \mathrm{mM}$ glucose plus $0.5 \mathrm{mM}$ palmitate were higher in the islets from the 'malnourished' compared with the control group. Moreover octanoate and the unsaturated fatty acids all elicited a greater increment in glucose-stimulated insulin release in the 'malnourished' group and the response was 

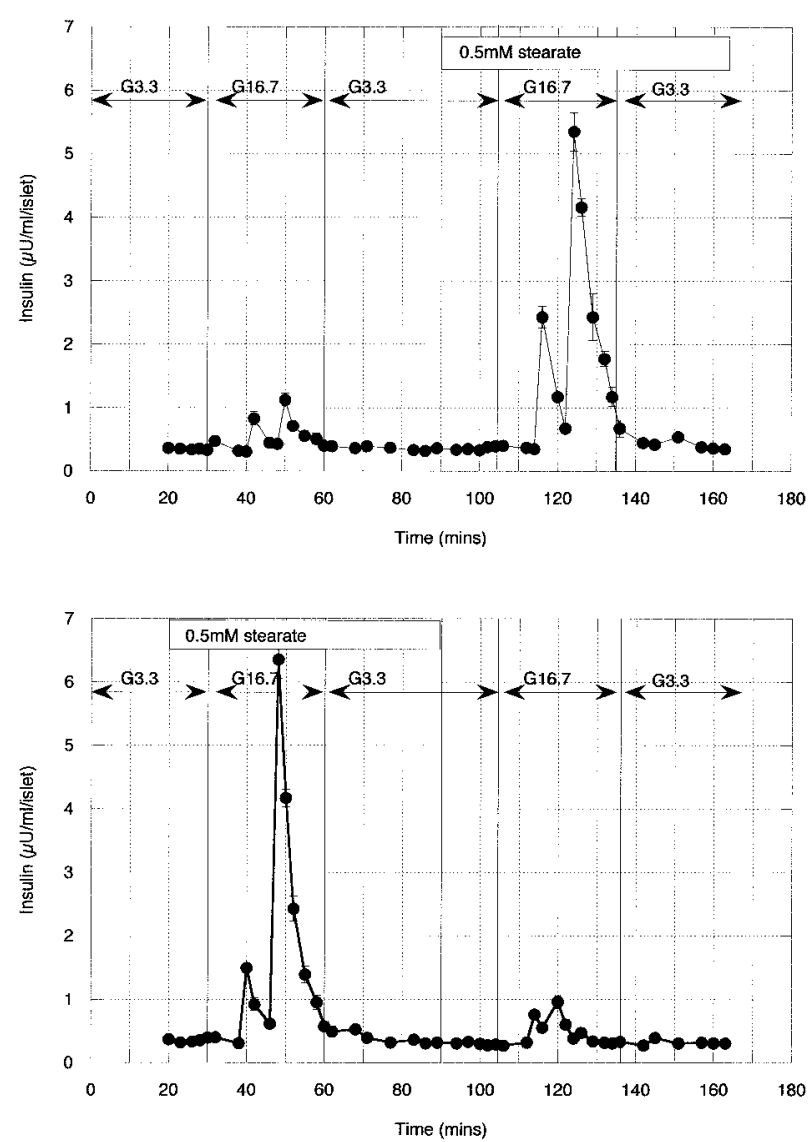

Figure 5 Potentiation by stearate of glucose-stimulated insulin release from perifused islets of rats whose mothers were fed a low-protein diet during the first 12 days of lactation. Each batch of islets was exposed to two stimulatory periods, either $16.7 \mathrm{mM}$ glucose (G16.7) followed by $16.7 \mathrm{mM}$ glucose plus $0.5 \mathrm{mM}$ stearate (Protocol A, upper panel) or the converse (Protocol B, lower panel) The stimulatory periods were separated by a non-stimulatory period in $3.3 \mathrm{mM}$ glucose $(\mathrm{G} 3 \cdot 3)$. Data are means \pm S.E.M. for four separate experiments.

present irrespective of whether the exposure to fatty acid occurred during the first glucose challenge or the second.

\section{Discussion}

Isolated islets of Langerhans maintain high rates of oxygen uptake in the absence of exogenous fuels (Hellerstrom 1967). Since the beta-cell contains little glycogen (Ashcroft et al. 1972) the main fuel store is likely to be triacylglycerol. However, rates of de novo fatty acid synthesis in islets are low (Berne 1975a); the fatty acid moieties of the triacylglycerol must therefore be derived from circulating fat fuels. Islets express low-density lipoprotein receptors (Grupping et al. 1997) and lipoprotein lipase (Cruz et al. 2001) and may therefore obtain fatty acids from lipoprotein particles. However, free fatty acids
Table 2 Insulin secretory responses to glucose and fatty acids (FAs) of perifused islets from rats whose mothers had been fed a low-protein diet during the first 12 days of lactation. Islets were perifused according to the protocols described in Materials and Methods. Each batch of islets was exposed to two $30 \mathrm{~min}$ stimulatory periods. In Protocol A the first stimulus was $16.7 \mathrm{mM}$ glucose and the second was $16.7 \mathrm{mM}$ glucose plus $0.5 \mathrm{mM}$ FA. In Protocol B the first stimulus was $16.7 \mathrm{mM}$ glucose plus $0.5 \mathrm{mM}$ FA and the second was $16.7 \mathrm{mM}$ glucose alone. The stimulations were separated by a non-stimulatory period ( $3.3 \mathrm{mM}$ glucose). The table presents the integrated insulin secretion during the two stimulatory periods. Data are means \pm S.E.M. of four separate experiments

\begin{tabular}{|c|c|c|c|c|}
\hline & \multirow[b]{2}{*}{ Protocol } & \multicolumn{2}{|c|}{$\begin{array}{l}\text { Insulin secretion ( } \mu \mathrm{U} / \text { islet) } \\
\text { in response to: }\end{array}$} & \multirow[b]{2}{*}{$P$} \\
\hline & & Glucose & Glucose+FA & \\
\hline \multicolumn{5}{|l|}{ FA } \\
\hline \multirow[t]{2}{*}{ Octanoate } & A & $16 \cdot 2 \pm 0 \cdot 8$ & $22 \cdot 6 \pm 0 \cdot 8$ & $<0 \cdot 001$ \\
\hline & B & $15 \cdot 4 \pm 0 \cdot 8$ & $28 \cdot 0 \pm 1 \cdot 2$ & $<0.001$ \\
\hline \multirow[t]{2}{*}{ Palmitate } & A & $14 \cdot 9 \pm 1 \cdot 0$ & $47 \cdot 7 \pm 2 \cdot 3$ & $<0.001$ \\
\hline & B & $13 \cdot 0 \pm 0 \cdot 7$ & $58 \cdot 4 \pm 2 \cdot 6$ & $<0.001$ \\
\hline \multirow[t]{2}{*}{ Stearate } & A & $15 \cdot 4 \pm 1 \cdot 1$ & $46 \cdot 6 \pm 2 \cdot 1$ & $<0 \cdot 001$ \\
\hline & B & $12 \cdot 3 \pm 1 \cdot 1$ & $44 \cdot 5 \pm 2 \cdot 0$ & $<0 \cdot 001$ \\
\hline \multirow[t]{2}{*}{ Palmitoleate } & A & $15 \cdot 5 \pm 0 \cdot 6$ & $27 \cdot 0 \pm 1 \cdot 3$ & $<0.001$ \\
\hline & B & $13 \cdot 7 \pm 1 \cdot 0$ & $31 \cdot 9 \pm 1 \cdot 5$ & $<0.001$ \\
\hline \multirow[t]{2}{*}{ Linoleate } & A & $18 \cdot 4 \pm 1 \cdot 9$ & $23 \cdot 5 \pm 1 \cdot 1$ & $<0.05$ \\
\hline & B & $18 \cdot 9 \pm 1 \cdot 0$ & $26 \cdot 7 \pm 1 \cdot 2$ & $<0.01$ \\
\hline \multirow[t]{2}{*}{ Elaidate } & A & $13 \cdot 3 \pm 1 \cdot 0$ & $27 \cdot 5 \pm 1 \cdot 2$ & $<0.001$ \\
\hline & B & $14 \cdot 8 \pm 1 \cdot 0$ & $27 \cdot 2 \pm 1 \cdot 5$ & $<0.001$ \\
\hline
\end{tabular}

are also taken up and stored or oxidised by islets (Berne 1975b). Exposure of islets to fatty acids has marked effects on secretory function. Prolonged exposure of rodent islets to fatty acids results in impairment of glucose-stimulated insulin release (Zhou \& Grill 1994). In Zucker diabetic fa/fa rats, which have mutated leptin receptors, a massive increase in islet triacylglycerol occurs, associated with increased $\mathrm{NO}$, oxidative damage, and beta-cell apoptosis (Unger 1997). Overexpression of leptin receptors prevents the accumulation of islet triacylglycerol and reverses the diabetes (Wang et al. 1998). There is also evidence that an increase in free fatty acid in man precedes a beta-cell defect predictive of type 2 diabetes (Paolisso et al. 1995, Charles et al. 1997).

There is thus strong evidence that chronic exposure to fatty acids is associated with pathological changes in the beta-cell that may be involved in diabetes. However, short-term exposure to fatty acids has generally been found to result in enhanced insulin secretion, both in rodents and in man, and Dobbins et al. (1998) have obtained evidence that an adequate level of free fatty acids plays an essential permissive role in glucose-stimulated insulin release. Whether different long-chain fatty acids exert distinct effects on insulin release has been controversial. No influence of the type of ingested fatty acid was reported in one in vivo study (Gatti et al. 1992), whereas other studies concluded preferential stimulation was 
elicited by polyunsaturated (Lardinois et al. 1987), monounsaturated (Joannic et al. 1997), or saturated (Rasmussen et al. 1996) fatty acids. In vitro studies have also yielded conflicting results. Palmitate and oleate had similar effects on rat islets (Conget et al. 1994) whereas in mouse islets oleate was reported to stimulate insulin release but palmitate was ineffective and stearate actually inhibited insulin release (Opara et al. 1994). There are also discrepant findings on the glucose concentration dependence of the secretory response to fatty acids. In perfused rat pancreas palmitate and stearate induced insulin secretion more effectively at low $(3 \mathrm{mM})$ rather than high $(12.5 \mathrm{mM})$ glucose (Stein et al. 1997), whereas the converse was reported for rat islets (Warnotte et al. 1999). Finally the magnitude of the response to fatty acids has also been inconsistent for palmitate values ranging from $70 \%$ to 17-fold have been variously reported (Stein et al. 1997, Warnotte et al. 1999).

In the present studies we have examined the effects of a range of fatty acids on insulin secretion at basal $(3.3 \mathrm{mM})$, sub-maximal $(8.3 \mathrm{mM})$, and maximally stimulating $(16.7 \mathrm{mM})$ glucose concentrations in rat islets of Langerhans. In agreement with Warnotte et al. (1999) we find that the effects of fatty acids are dependent on: (i) glucose concentration, the largest stimulation occurring at high glucose; (ii) chain length, with $16: 0$ and 18:0 being much more effective than 8:0; and (iii) saturation, with saturated fatty acids being more effective than unsaturated. The dependence on chain length and degree of saturation were found both in batch incubations and in perifused islets.

To assess the applicability of these findings to man we carried out parallel studies on human islets of Langerhans. As for rat islets, human islets were optimally stimulated by long-chain, unsaturated fatty acids at high glucose concentrations.

Since these data clearly indicate that insulin secretion is sensitive to changes in both glucose and fatty acid levels, it is important to establish whether responses to these two nutrients are obligatorily coupled or whether the sensitivity to one can vary independently of that to the other. To investigate this point we used an animal model of impaired insulin secretion (Moura et al. 1996). In this model, female rats are fed a low-protein diet during the first 14 days of lactation. Subsequently both they and their offspring are fed normal laboratory diet. The islets of the offspring at age 60 days are shown here, in agreement with in vivo data (Moura et al. 1996), to display a subnormal insulin secretory response to glucose in both batch and perifusion studies. Despite this attenuated glucose response, the islets responded well to fatty acids. Indeed there was some evidence for enhanced sensitivity to fatty acids, since both medium-chain (8:0) and unsaturated (16:1 and 18:2) fatty acids were more effective on the islets from rats with malnourished mothers than on those from control litter mates. These findings emphasise the complex nature of the interrelationship of nutrients in the regulation of insulin secretion. They also reinforce the concept that fat fuels play an important role in glucose homeostasis in response to undernourishment.

\section{Acknowledgements}

These studies were supported by the Islet Research European Latin American Network and by the Wellcome Trust. We are very grateful to Dr Roger James and colleagues, University of Leicester, for providing human islets of Langerhans. We thank Carine Beysen for help in making fatty acid solutions.

\section{References}

Alstrup KK, Gregersen S, Jensen HM, Thomsen JL \& Hermansen K 1999 Differential effects of cis and trans fatty acids on insulin release from isolated mouse islets. Metabolism 48 22-29.

Ashcroft SJH, Weerasinghe LCC, Bassett JM \& Randle PJ 1972 The pentose cycle and insulin release in mouse pancreatic islets. Biochemical Journal 126 525-532.

Balasse EO \& Ooms HA 1973 Role of plasma free fatty acids in the control of insulin secretion in man. Diabetologia 9 145-151.

Berne C 1975a The metabolism of lipids in mouse pancreatic islets. The biosynthesis of triacylglycerols and phospholipids. Biochemical Journal 152 667-673.

Berne C $1975 b$ The metabolism of lipids in mouse pancreatic islets. The oxidation of fatty acids and ketone bodies. Biochemical Journal 152 661-666.

Boden G, Chen XH \& Iqbal N 1998 Acute lowering of plasma fatty acids lowers basal insulin secretion in diabetic and nondiabetic subjects. Diabetes 47 1609-1612.

Bollheimer LC, Skelly RH, Chester MW, McGarry JD \& Rhodes CJ 1998 Chronic exposure to free fatty acid reduces pancreatic $\beta$-cell insulin content by increasing basal insulin secretion that is not compensated for by a corresponding increase in proinsulin biosynthesis translation. Journal of Clinical Investigation 101 1094-1101.

Charles MA, Eschwege E, Thibult N, Claude JR, Warnet JM, Rosselin GE, Girard J \& Balkau B 1997 The role of non-esterified fatty acids in the deterioration of glucose tolerance in Caucasian subjects: results of the Paris Prospective Study. Diabetologia 40 1101-1106.

Conget I, Rasschaert J, Sener A, Leclercq-Meyer V, VillanuevaPenacarrillo M, Valverde I \& Malaisse WJ 1994 Secretory, biosynthetic, respiratory, cationic, and metabolic responses of pancreatic islets to palmitate and oleate. Biochemical Medicine and Metabolic Biochemistry 51 175-184.

Crespin SR, Greenough WB \& Steinberg D 1973 Stimulation of insulin secretion by long-chain free fatty acids. A direct pancreatic effect. Journal of Clinical Investigation 52 1979-1984.

Cruz WS, Kwon G, Marshall CA, McDaniel ML \& Semenkovich CF 2001 Glucose and insulin stimulate heparin-releasable lipoprotein lipase activity in mouse islets and INS-1 cells. A potential link between insulin resistance and beta-cell dysfunction. Journal of Biological Chemistry 276 12162-12168.

Dobbins RL, Chester MM, Daniels MB, McGarry JD \& Stein DT 1998 Circulating fatty acids are essential for efficient glucosestimulated insulin secretion after prolonged fasting in humans. Diabetes 47 1613-1618. 
Elks ML 1993 Chronic perifusion of rat islets with palmitate suppresses glucose-stimulated insulin release. Endocrinology 133 208-214.

Gatti E, Noe D, Pazzucconi F, Gianfranceshi G, Porrini M, Testolin G \& Sirtori CR 1992 Differential effects of unsaturated oils and butter on blood glucose and insulin response to carbohydrate in normals. European Journal of Clinical Nutrition 46 1284-1289.

Greenough WB, Crespin SR \& Steinberg D 1967 Hypoglycaemia and hyperinsulinaemia in response to raised free-fatty acid levels. Lancet 2 1334-1336.

Grill V \& Qvigstad E 2000 Fatty acids and insulin secretion. British Journal of Nutrition 83 S79-S84.

Grupping AY, Cnop M, Van Schravendijk CFH, Hannaert JC, Van Berkel TJC \& Pipeleers DG 1997 Low density lipoprotein binding and uptake by human and rat islet $\beta$-cells. Endocrinology 138 4064-4068.

Hellerstrom C 1967 Effects of carbohydrates on the oxygen consumption of isolated pancreatic islets of mice. Endocrinology $\mathbf{8 1}$ 105-112.

Joannic JL, Auboiron S, Raison J, Basdevant A, Bornet F \& Guy-Grand B 1997 How the degree of unsaturation of dietary fatty acids influences the glucose and insulin responses to different carbohydrates in mixed meals. American Journal of Clinical Nutrition 65 1427-1433.

Lardinois CK, Starich GH, Mazzaferri EL \& DeLett A 1987 Polyunsaturated fatty acids augment insulin secretion. Journal of the American College of Nutrition 6 507-515.

McGarry JD \& Dobbins RL 1999 Fatty acids, lipotoxicity and insulin secretion. Diabetologia 42 128-138.

Molnár E, Váradi A, McIlhinney RAJ \& Ashcroft SJH 1995 Identification of functional ionotropic glutamate receptor proteins in pancreatic B-cells and in islets of Langerhans. FEBS Letters 371 253-257.

Moura AS, Carpinelli AR, Barbosa FB, Gravena C \& Mathias PC 1996 Undernutrition during early lactation as an alternative model to study the onset of diabetes mellitus type I. Research Communications in Molecular Pathology and Pharmacology 92 73-84.

Opara EC, Garfinkel M, Hubbard VS, Burch WM \& Akwari OE 1994 Effect of fatty acids on insulin release: role of chain length and degree of unsaturation. American Journal of Physiology 266 E635-E639.

Paolisso G, Tataranni PA, Foley JE, Bogardus C, Howard BV \& Ravussin E 1995 A high concentration of fasting plasma non-esterified fatty acids is a risk factor for the development of NIDDM. Diabetologia 38 1213-1217.
Rasmussen O, Lauszus FF, Christiansen C, Thomsen C \& Hermansen K 1996 Differential effects of saturated and monounsaturated fat on blood glucose and insulin responses in subjects with non-insulindependent diabetes mellitus. American Journal of Clinical Nutrition 63 249-253.

Sako Y \& Grill VE 1990 A 48-hour lipid infusion in the rat timedependently inhibits glucose-induced insulin secretion and B cell oxidation through a process likely coupled to fatty acid oxidation. Endocrinology 127 1580-1589.

Seyffert WJ \& Madison L 1967 Physiologic effects of metabolic fuels on carbohydrate metabolism. I. Acute effect of elevation of plasma free fatty acids on hepatic glucose output, peripheral glucose utilization, serum insulin and plasma glucagon levels. Diabetes 16 765-776.

Stein DT, Esser V, Stevenson BE, Lane KE, Whiteside JH, Daniels MB, Chen S \& McGarry JD 1996 Essentiality of circulating fatty acids for glucose-stimulated insulin secretion in the fasted rat. Journal of Clinical Investigation 97 2728-2735.

Stein DT, Stevenson BE, Chester MW, Basit M, Daniels MB, Turlet SD \& McGarry JD 1997 The insulinotropic potency of fatty acids is influenced profoundly by their chain length and degree of saturation. Journal of Clinical Investigation 100 398-403.

Sutton R, Peters M, McShane P, Gray DWR \& Morris PJ 1986 An improved method for the isolation of islets of Langerhans from the adult rat pancreas. Transplantation Proceedings 18 1819-1820.

Unger RH 1997 How obesity causes diabetes in Zucker diabetic fatty rats. Trends in Endocrinology and Metabolism 8 276-282.

Wang MY, Koyama K, Shimabukuro M, Mangelsdorf D, Newgard CB \& Unger RH 1998 Overexpression of leptin receptors in pancreatic islets of Zucker diabetic fatty rats restores GLUT-2, glucokinase, and glucose-stimulated insulin secretion. PNAS 95 11921-11926.

Warnotte C, Nenquin M \& Henquin JC 1999 Unbound rather than total concentration and saturation rather than unsaturation determine the potency of fatty acids on insulin secretion. Molecular and Cellular Endocrinology 153 147-153.

Zhou Y-P \& Grill VE 1994 Long-term exposure of rat pancreatic islets to fatty acids inhibits glucose-induced insulin secretion and biosynthesis through a glucose fatty acid cycle. Journal of Clinical Investigation 93 870-876.

Received 27 September 2001 Accepted 28 November 2001 